IFN Working Paper No. 1393, 2021

\title{
Vox Populi, Vox Dei? Tacit Collusion in Politics
}

Christian Johansson, Anders Kärnä and Jaakko Meriläinen 


\title{
Vox Populi, Vox Dei? Tacit Collusion in Politics
}

\author{
Christian Johansson ${ }^{\dagger}$, Anders Kärnä*‡, and Jaakko Meriläinen* \\ ${ }^{\dagger}$ Chalmers University of Technology \& University of Gothenburg \\ $\ddagger$ Örebro University \& the Research Institute of Industrial Economics (IFN) \\ \&ITAM
}

\begin{abstract}
We study competition between political parties in repeated elections with probabilistic voting, allowing a multidimensional policy space and multiple political parties. This model entails multiple equilibria. When parties hold different opinions on some policy, they may take different policy positions that do not coincide with the median voter's preferred policy platform but converge towards it. In contrast, when parties have a mutual understanding on a particular policy, their policy positions may converge (on some dimension) but not to the median voter's preferred policy. Parties may collude with one another and take a position that differs from what the median voter prefers, despite political competition. Collusion may collapse, for instance, after the entry of a new political party. We substantiate the theoretical arguments with descriptive evidence using Swedish survey data on politicians and voters, which suggests that there is competition on some dimensions and collusion on others.
\end{abstract}

Keywords: electoral competition, partisan collusion, probabilistic voting, repeated elections, tacit collusion

JEL: C73, D72, P16

${ }^{*}$ We are grateful to Peter Buisseret, Andrei Gomberg, Anders Sundell, and seminar participants at Örebro University and the Gothenburg Research Group on Elections, Public Opinion and Political Behavior (GEPOP) for helpful comments and discussions. Jakob Ahlbom has been of extraordinary assistance with the data. Financial support for Anders Kärnä from Jan Wallanders och Tom Hedelius stiftelse (grant P2018-0162) is gratefully acknowledged. Corresponding author: anders.karna@ifn.se; IFN, Box 55665, 102 15 Stockholm, Sweden. 


\section{Introduction}

At the heart of many normative definitions of democratic systems is the assertion that political parties represent their constituents and advocate for them in the policy-making process (Dahl, 1956). This definition, however, is somewhat at odds with a set of empirical observations. Empiricists have shown that political parties matter for policy outcomes in both two-party (Lee, Moretti and Butler, 2004; Ferreira and Gyourko, 2009) and multiparty systems (Folke, 2014; Pettersson-Lidbom, 2008). Moreover, politicians have vastly different views from their voters (Levitt, 1996; Ansolabehere, Snyder and Stewart, 2001). This could be due to factors such as elite misperceptions of public opinion (Broockman and Skovron, 2018; Pereira, Forthcoming), differences in the personal characteristics of political elites and masses (Lasch, 1996; Kertzer, Forthcoming), or the nature of political competition (Gerber and Lewis, 2004).

The notion that politicians' and citizens' policy preferences do not coincide is evidently in conflict with the classical work in formal political theory where the policy platforms of two competing parties converge to the median voter's preferred policy position. A prominent example of this theoretical work is the economic theory of democracy by Downs (1957) and extensions thereof (see Grofman 2004 for a review).

We address this discrepancy by formulating a probabilistic voting model that allows a multidimensional policy space and multiple political parties. In the equilibria that this model entails, parties may take two types of policy positions depending on the underlying circumstances:

(i) When parties hold different opinions on some policy, they may take different policy positions that do not coincide with the median voter's preferred policy platform.

(ii) When parties have a mutual understanding of a particular policy, their policy positions may converge (on some dimension) but not to the median voter's preferred policy. 
Parties may collude with one another and take a position that differs from what the median voter prefers, despite political competition.

Our model shares some similarities with the probabilistic spatial voting model of Lin, Enelow and Dorussen (1999), but we deviate from their treatise in two ways. ${ }^{1}$ The first deviation is small: Our model allows a continuous rather than a discrete policy space. The second difference is that candidates do not simply attempt to maximize their expected number of votes but also have personal policy preferences. Thus, their utility function balances their personal policy preferences with their expected electoral performance and the influence they expect to gain over policy.

Similar to Alesina (1988), among others, we model electoral competition as a repeated game (see also Duggan and Martinelli 2017 for a review). One rationale for doing so is the remarkable stability of party systems observed especially in the West: Although parties are organizations that react to changing circumstances, they are also persistent institutions (Aldrich, 1995; Bartolini and Mair, 2007). A fundamental advantage of this approach is that it allows us to characterize the second type of equilibria, the collusion equilibria. This is the main novelty and contribution of our paper. Examples of partisan collusion (and its consequences) could be drawn from diverse contexts. For instance, Gottlieb (2015) argues that the low level of public goods provision in villages in Mali is a result of collusion between rent-seeking political parties. According to Crisp and Desposato (2004), incumbent representatives collude with one another to use state resources to advance their own electoral careers in Colombia. Similarly, Katz and Mair (1995) discuss collusion between political parties - what they call the "cartel party" - to employ state resources for their political survival. They present examples of such noncompetitive party behavior in a number of established democracies.

\footnotetext{
${ }^{1}$ Adams (1999) is another example of a model of policy divergence in a multicandidate probabilistic voting setup. See also Lindbeck and Weibull (1987) for early work on probabilistic voting and Persson and Tabellini (2002) for a textbook treatise.
} 
Importantly, we argue that the collusion equilibria can break down if there is a shock to the location of the median voter or if there are changes in the configuration of the party system. In such cases, convergence towards the median voter's policy position may emerge. This result reconciles many empirical findings that document shifts in politicians' and parties' policy platforms and their causes. ${ }^{2}$ The rise of populist parties in Western Europe and the subsequent response of mainstream parties serves as a timely example. Established political parties have become more moderate along social dimensions of ideology, which has provided new parties with an opportunity to take more extreme policy positions and thereby benefit electorally (e.g., Rydgren 2007). Many researchers have argued and shown that mainstream parties have reacted to the rise of the radical right by adjusting their own policy positions on issues such as immigration and European integration (e.g., Meijers 2017; Abou-Chadi and Krause 2020; Spoon and Klüver 2020). ${ }^{3}$ This is in line with the idea of new parties acting as political entrepreneurs that offer new policy options to the voters and, by doing so, defy the established party brands (De Vries and Hobolt, 2020).

A natural parallel could be drawn between collusion among political parties and the work on tacit collusion between firms (see Ivaldi et al. 2003 for a review). ${ }^{4}$ When political parties repeatedly compete with one another, they may form a cartel and hold policy positions that are favorable to them but harmful to voter welfare. Similarly, repeated interactions among firms could lead to collusion where firms maintain higher prices, lower quality, or something else that can make consumers worse off. This collusion can be upheld if the parties or the firms tacitly agree that any deviation from the collusive equilibrium would trigger retaliation that would dominate the potential short-term benefits of drifting away from the collusive path. A focal point, for example a price ceiling as in Knittel and Stango (2003) or a shared

\footnotetext{
${ }^{2}$ Adams (2012) surveys both theoretical and empirical literature on shifts in parties' policy platforms in multiparty settings.

${ }^{3}$ Populists could also be successful in changing the pubic norms, making it socially acceptable to express views that were previously stigmatized (Bursztyn, Egorov and Fiorin, 2020).

${ }^{4}$ A classic example of an industrial-organization take on the study of political organizations is Weingast and Marshall (1988). More recently, Seror and Verdier (2018) adopted a similar approach to studying political parties. Their model is closely related to ours and that of Lin, Enelow and Dorussen (1999), but they do not discuss the possibility of political cartels.
} 
political view along some policy dimension as in our model, can make co-operation more viable.

We are not the first to theoretically discuss the idea of tacit collusion in the political arena. Palfrey (1984) and Weber (1992) present formal models in which two candidates collude to take divergent policy positions in a single-dimensional policy space in response to the threat of an outside entrant. ${ }^{5}$ In that respect, their equilibrium prediction differs from our collusion equilibria in a fundamental way. Furthermore, contrary to Palfrey (1984) and Weber (1992), we do not consider a static framework but instead study a setting where parties participate in a sequence of elections.

Collusion is of course not the only potential explanation for why parties' policy platforms might not converge. Wittman (1983) and Calvert (1985) showed in their seminal work that if there is uncertainty about the electoral outcome and parties have divergent preferences over policy, divergence can arise if candidates "sacrifice" part of winning probability to adopt policy platform that are more aligned with their preferences. If voters also care about factors that are independent of policy positions - such as different valence characteristics (Stokes, 1963) - divergence may arise if some candidates wish to avoid competition with more qualified candidates in a crowded policy space or if some candidates use their quality advantage to deviate from the median voter's preferred policies (Ansolabehere and Snyder, 2000; Groseclose, 2001; Ashworth and Bueno de Mesquita, 2009). Furthermore, if candidates (or parties) have some personal policy preferences that are different from those of the median voter, and they cannot credibly commit to deviating from them, we would observe divergent policy platforms (Alesina, 1988; Osborne and Slivinski, 1996; Besley and Coate, 1997).

We conclude the paper by substantiating our theoretical arguments with descriptive evidence from Sweden. This exercise combines data on Swedish voters' and politicians' policy preferences. ${ }^{6}$ Using these extraordinarily detailed data, we document that, on average,

\footnotetext{
${ }^{5}$ In a related contribution comparing corrupt behavior of politicians across electoral systems, Myerson (1993) notes the possibility of collusion in two-party systems.

${ }^{6}$ See Ågren, Dahlberg and Mörk (2007) and Pereira (Forthcoming) for examples of other studies using these data.
} 
politicians' and citizens' economic policy preferences are remarkably similar, even after controlling for a host of individual-level characteristics. However this does not hold true for other dimensions of policy-making. For instance, we show a large and persistent gap between political elites' and citizens' opinions on accepting more refugees into the country. Interestingly, the opinions of voters and politicians become similar (on average) around the European refugee crisis and the time when a new populist party makes a breakthrough in national politics. These empirical observations could be rationalized by there being a party cartel that then breaks apart when the political environment changes, similar to the possible effect of entry on tacit collusion among firms (Brander and Spencer, 1985; MacLeod and Norman, 1987).

\section{The Model}

In this section, we present a simple but general model of electoral competition with probabilistic voting. We start by laying out a version with office-motivated candidates and then augment the model by introducing policy motivations. By studying the dynamics of the latter version of the model, we illustrate that, under certain conditions, parties may collude with one another and take policy positions further away from the median voter.

\subsection{Electoral Competition with Vote-Seeking Candidates}

We begin by describing a continuous version of the model from Lin, Enelow and Dorussen (1999). Let there be $n$ candidates who compete for the votes of a population of voters in the policy space. For simplicity, we assume that the policy space is 2-dimensional real space $\mathbf{R}^{2}{ }^{7}$ We assume that the voters are distributed in $\mathbf{R}^{2}$ according to the probability density function $g$. The candidates choose positions $c_{1}, \ldots, c_{n} \in \mathbf{R}^{2}$, and they commit to enacting

\footnotetext{
${ }^{7}$ Given that our main goal is to show that we may have competition on one policy dimension and collusion on another, two dimensions suffice. However, it is straightforward to generalize the model to allow for $m$ policy dimensions (where $m \geq 1$ is an integer) by simply replacing $\mathbf{R}^{2}$ with $\mathbf{R}^{m}$ in what follows. Propositions 1 and 3 also hold when $\mathbf{R}^{2}$ is replaced by $\mathbf{R}^{m}$, with only superficial changes to the proofs.
} 
these policies after the election. Let

$$
d: \mathbf{R}^{2} \times \mathbf{R}^{2} \rightarrow \mathbf{R}_{\geq 0}
$$

denote a distance function on $\mathbf{R}^{2}$. The policy promised by candidate $i$ yields each voter with position $v \in \mathbf{R}^{2}$ utility

$$
U_{v}(i)=E_{i}-d\left(v, c_{i}\right)
$$

where $E_{i}$ is a continuous random variable. The probabilistic element of the model depends on the candidate but not on the voters. We assume that $E_{i}$ are independent with mean 0 .

We can now compute the expected vote share of candidate 1 (the expressions for other candidates are entirely analogous). A voter with position $v$ will vote for candidate 1 if $U_{v}(1)>U_{v}(i)$ for all $i \geq 2$. This condition is easily rewritten as

$$
E_{i}-E_{1}<d\left(v, c_{i}\right)-d\left(v, c_{1}\right)
$$

Let us denote $E_{i 1}:=E_{i}-E_{1}$ and $D_{i 1}(v)=d\left(v, c_{i}\right)-d\left(v, c_{1}\right)$. Furthermore, let us write $\mathbf{E}_{1}:=\left(E_{21}, \ldots, E_{n 1}\right)$; this is a multivariate random variable, and we denote its joint cumulative density function by $F$ and its joint probability density function by $f$. Similarly, we set $\mathbf{D}_{1}(v)=\left(D_{21}(v), \ldots, D_{n 1}(v)\right)$. The probability that a voter with position $v$ votes for candidate 1 is then

$$
P_{1}(v):=\mathbf{P}\left(\mathbf{E}_{1}<\mathbf{D}_{1}(v)\right)=F\left(\mathbf{D}_{1}(v)\right)
$$

and therefore, the expected vote share of candidate 1 is

$$
E V_{1}:=\int_{\mathbf{R}^{2}} g(v) P_{1}(v) d v=\int_{\mathbf{R}^{2}} g(v) F\left(\mathbf{D}_{1}(v)\right) d v
$$

Lin, Enelow and Dorussen (1999) derive general conditions for the existence of Nash equilibria when candidates attempt to maximize their expected vote share. Nevertheless, 
any more detailed analysis of their model, such as locating a Nash equilibrium, is difficult without specifying the shape of $g, F$, and the distance function $d$. Before proceeding to a version with policy-motivated candidates, let us record a median voter result from this probabilistic spatial voting model under a particular set of assumptions.

Proposition 1. Assume that there is a median (and mean) voter, with position $0 \in \mathbf{R}^{2}$, $n=2$ and that $d$ is a strictly decreasing positive function of Euclidean distance on $\mathbf{R}^{2}$. Assume further that $g(v)=h(d(v, 0))$ for some nonincreasing function $h: \mathbf{R}_{\geq 0} \rightarrow \mathbf{R}_{\geq 0}$ and that $f$ is an even function (i.e., symmetric around $0 ; f(x)=f(-x)$ ). Then, $E V_{1} \geq 1 / 2$ if and only if $d\left(c_{1}, 0\right) \leq d\left(c_{2}, 0\right)$. If, additionally, $h$ is decreasing, then $E V_{1}>1 / 2$ if and only if $d\left(c_{1}, 0\right)<d\left(c_{2}, 0\right)$. In particular, there is a unique Nash equilibrium $c_{1}=c_{2}=0$.

Proof. If $c_{1}=c_{2}$ then it is clear that $E V_{1}=1 / 2$. Thus, assume that $c_{1} \neq c_{2}$. Let $L$ denote the line in $\mathbf{R}^{2}$ that is perpendicular to the line through $c_{1}$ and $c_{2}$ and goes through $\left(c_{1}+c_{2}\right) / 2$. Let $R$ be the reflection on $\mathbf{R}^{2}$ that fixes $L$, and let $H_{1}$ and $H_{2}$ be the two closed half-planes with boundary $L$; we assume $c_{i} \in H_{i}$. The situation is symmetric, so assume that $d\left(c_{1}, 0\right) \leq d\left(c_{2}, 0\right)$, i.e., that $0 \in H_{1}$. Note that $d(v, w) \leq d(R(v), w)$ for all $v, w \in H_{1}$, and note that $R\left(c_{1}\right)=c_{2}$. We then compute

$$
\begin{gathered}
E V_{1}=\int_{\mathbf{R}^{2}} g(v) F\left(\mathbf{D}_{1}(v)\right) d v=\int_{H_{1}} g(v) F\left(D_{21}(v)\right)+g(R v) F\left(D_{21}(R(v))\right) d v= \\
=\int_{H_{1}} g(v) F\left(D_{21}(v)\right)+g(R v)\left(1-F\left(D_{21}(v)\right)\right) d v
\end{gathered}
$$

Here, we have used that $D_{21}(R(v))=-D_{21}(v)$ (which follows from the remarks above) and that, since $f$ is even, $F(-x)=1-F(x)$. Similarly, one sees that

$$
E V_{2}=1-E V_{1}=\int_{H_{1}} g(v)\left(1-F\left(D_{21}(v)\right)\right)+g(R v) F\left(D_{21}(v)\right) d v
$$


The proposition now follows by noting that

$$
g(v) F\left(D_{21}(v)\right)+g(R v)\left(1-F\left(D_{21}(v)\right)\right) \geq g(v)\left(1-F\left(D_{21}(v)\right)\right)+g(R v) F\left(D_{21}(v)\right)
$$

since $g(v) \geq g(R(v))$ and $F\left(D_{21}(v)\right) \geq 1 / 2$ when $v \in H_{1}$. Here, we use the inequality $a c+b(1-c) \geq a(1-c)+b c$ when $c \in[1 / 2,1]$ and $a \geq b \geq 0$.

\subsection{Probabilistic Voting with Policy-Motivated Candidates}

Suppose then that the candidates will not merely attempt to maximize their expected vote share. Instead, they care about the outcome of policy-making. Let each candidate $i$ have a preferred policy $\tilde{c}_{i} \in \mathbf{R}^{2}$. Candidate $i$ derives utility

$$
\tilde{U}_{i}\left(c_{1}, \ldots, c_{n}\right)=\sum_{j=1}^{n} E V_{j} \cdot W\left(d\left(c_{j}, \tilde{c}_{i}\right)\right)
$$

from the announced policies $c_{1}, \ldots, c_{n}$. The utility for candidate $i$ of the policies $c_{1}, \ldots, c_{n}$ is a weighted sum over $j$ of the extent to which candidate $i$ likes policy $c_{j}$ (modeled by the term $W\left(d\left(c_{j}, \tilde{c}_{i}\right)\right)$, where $W: \mathbb{R}_{\geq 0} \rightarrow \mathbb{R}$ is a strictly decreasing function) and how large the influence of candidate $j$ will be, which we simply quantify by the expected vote share $E V_{j}$.

While candidate $i$ will commit to policy $c_{i}$ after the election in our model, we do not assume that the winner of the election alone sets the policy. As it is formulated, the model describes a situation where the opposition can exert some influence over policy (and the general political climate). In situations where $n>2$, it is also reasonable to expect that no single party will have a majority and that even smaller parties will influence the policy outcome. $^{8}$

Our main focus is on the formation of political cartels over time, with an uncertain time horizon. Therefore, we are primarily interested in the repeated game rather than the oneshot game (c.f. Alesina 1988). We model the uncertain time horizon as an infinite time

\footnotetext{
${ }^{8}$ See, for instance, Folke (2014) for empirical evidence supporting this claim.
} 
horizon, with the payoff function

$$
\sum_{k=0}^{\infty} \lambda^{k} \tilde{U}_{i}\left(c_{1}^{(k)}, \ldots, c_{n}^{(k)}\right),
$$

for candidate $i$. Here, $c_{i}^{(k)}$ denotes the selected policy of candidate $i$ at time $k$, and $0<\lambda<1$ is a discounting factor. If $\lambda$ is "large enough", candidates will participate for the foreseeable future.

Let us make one further remark regarding the utility function before we proceed to describe the collusion equilibria in our model. One may also specify the utility function of candidate $i$ as follows:

$$
\tilde{U}_{i}\left(c_{1}, \ldots, c_{n}\right)=\sum_{j=1}^{n} I_{i j}\left(E V_{1}, \ldots, E V_{n}\right) W_{i j}\left(c_{j}, \tilde{c}_{i}\right) .
$$

This utility function is again a weighted sum. The expression $I_{i j}\left(E V_{1}, \ldots, E V_{n}\right)$ quantifies the perceived influence of candidate $j$ under election outcome $\left(E V_{1}, \ldots, E V_{n}\right)$ in the eyes of candidate $i$. The expression $W_{i j}\left(c_{j}, \tilde{c}_{i}\right)$ quantifies how candidate $i$ values policy $c_{j}$ when enacted by candidate $j$. The simple model that we present here corresponds to setting $I_{i j}\left(E V_{1}, \ldots, E V_{n}\right)=E V_{j}$ and $W_{i j}\left(c_{j}, \tilde{c}_{i}\right)=W\left(d\left(c_{j}, \tilde{c}_{i}\right)\right)$ for all $i$ and $j$. The additional generality allows for more subtle weighting of election outcomes and policies. For example, candidates may place greater (or lesser) emphasis on their expected vote share depending on what kind of motivations are driving them (Callander, 2008). A candidate could also value one policy dimension more than another, which echoes issue ownership or party-level salience of certain policy issues (van der Brug, 2004). ${ }^{9}$ Finally, we could allow candidates to value a policy differently depending on which candidate enacts it. One could interpret this as the possibility of engaging in partisan collusion fundamentally depending on the relationship between two or more political parties.

\footnotetext{
${ }^{9}$ However, note that in our model, voters do not have the option of placing different weights on different policies. Incorporating this would require more fundamental changes to our spatial voting model.
} 


\subsection{Collusion Equilibria}

We now turn to discuss collusion equilibria in the game with repeated elections. Of course, the exact dynamics depend on $g, F, W$ and $\tilde{c}_{i}$, and hence little can be said without specifying them. Even after specifying them, a simulation is required to analyze the model. Before examining the simulation results, we will discuss how collusion can appear in our model.

A repeated game provides us with an opportunity to find equilibria through the mechanism behind the folk theorem, which we now briefly recall. In a repeated game like ours, the threat vector is the vector $\left(T h_{1}, \ldots, T h_{n}\right)$ of payoffs with first coordinate

$$
T h_{1}=\min _{\left(c_{2}, \ldots, c_{n}\right)} \max _{c_{1}} \tilde{U}_{1}\left(c_{1}^{(k)}, \ldots, c_{n}^{(k)}\right)
$$

and the other coordinates $T h_{2}, \ldots, T h_{n}$ similarly defined. Any set of plays $c_{1}, \ldots, c_{n}$ satisfying $\tilde{U}_{i}\left(c_{1}, \ldots, c_{n}\right)>T h_{i}$ for all $i$ gives rise to a Nash equilibrium (for sufficiently large $\lambda$ ) by candidate $i$ playing $c_{i}$ until someone, say candidate $j$, defects, and then everyone else reverts to playing the policies that min-max candidate $j$.

These equilibria are very rigid and may seem unrealistic, in that any deviation from a predetermined status quo is punished immediately, to the detriment of all. There are various ways to take the edge off of this. One option is to use a different game-theoretic notion of equilibrium. For example, one might consider approximate Nash equilibria to soften the effect of grim trigger strategies or consider correlated equilibria to allow movement between different sets of policies that are Pareto improvements of the threat vector. Here, we instead consider a more flexible way of using the threat vector to create collusion equilibria. Let us call a collection $X_{1}, \ldots, X_{n} \subseteq \mathbf{R}^{2}$ of regions a set of collusion regions if, for any set of plays $\left(c_{1}, \ldots, c_{n}\right) \in X_{1} \times \cdots \times X_{n}$

$$
\tilde{U}_{i}\left(c_{1}, \ldots, c_{n}\right)>T h_{i}
$$


for all $i{ }^{10}$ We may then consider a restricted game where candidate $i$ is only allowed to play policies from the region $X_{i}$. The following proposition is then immediate.

Proposition 2. With notation as above, any Nash equilibrium of the one-shot restricted game where candidate $i$ is only allowed to play policies from the region $X_{i}$ gives rise to a Nash equilibrium of the (unrestricted) repeated game (for any sufficiently large $\lambda$ ).

When the $X_{i}$ are singletons, this returns the previous "rigid" collusion equilibria. We interpret the proposition (and, more generally, the notion of collusion regions and the corresponding restricted game) as allowing competition within the restricted set of allowed collusion policies $X_{i}$, but moving outside of these regions is punished by the other candidates playing the threat.

Before proceeding to the numerical simulations, let us provide a stylized example of a situation where we have collusion regions when the assumptions of Proposition 2 are met.

Proposition 3. We make the same assumptions as in Proposition 1. Assume further that $d\left(0, \tilde{c}_{1}\right)=d\left(0, \tilde{c}_{2}\right)$. Let $X \subseteq \mathbf{R}^{2}$ be the line segment between $\tilde{c}_{1}$ and $\tilde{c}_{2}$. If

$$
\frac{W(0)+W\left(d\left(0, \tilde{c}_{i}\right)\right)}{2}<\min _{v \in X} W\left(d\left(v, \tilde{c}_{i}\right)\right)
$$

for $i=1,2$, then $X_{1}=X_{2}=X$ is a set of collusion regions.

Proof. By symmetry, it suffices to treat candidate 1 . Let $\left(c_{1}, c_{2}\right) \in X \times X$ be any play. Let $M_{i}=\min _{v \in X} W\left(d\left(v, \tilde{c}_{i}\right)\right)$. Then,

$$
\tilde{U}_{1}\left(c_{1}, c_{2}\right)=E V_{1} \cdot W\left(d\left(c_{1}, \tilde{c}_{1}\right)\right)+E V_{2} \cdot W\left(d\left(c_{2}, \tilde{c}_{1}\right)\right) \geq M_{1}>\frac{W(0)+W\left(d\left(0, \tilde{c}_{1}\right)\right)}{2} .
$$

On the other hand we claim that $T h_{1} \leq\left(W(0)+W\left(d\left(0, \tilde{c}_{1}\right)\right)\right) / 2$. Indeed, if candidate 2 plays policy $c_{2}=0$, we have $E V_{1} \leq 1 / 2$ (by Proposition 1 ) and $W\left(d\left(c_{1}, \tilde{c}_{1}\right)\right) \leq W(0)$ (since

\footnotetext{
${ }^{10}$ For some similar ideas in a context of a model with a dynamic oligopoly, see Fershtman and Pakes (2000).
} 
$W$ is decreasing). In particular,

$$
T h_{1} \leq \tilde{U}_{1}\left(c_{1}, 0\right) \leq\left(W(0)+W\left(d\left(0, \tilde{c}_{1}\right)\right)\right) / 2
$$

as desired. This finishes the proof.

\section{$3 \quad$ Numerical Results}

Simulation is the best tool to further illustrate our model and the collusion equilibria. Next, we present two numerical examples: one with two political parties and one where a third party enters. ${ }^{11}$

\subsection{Preliminaries}

To be able to make computations, one needs to specify $n, d, g$, the $E_{i}$, and $W$. We will consider the cases of $n=2$ and $n=3$. It seems natural to assume that the voters are distributed according to independent mean 0 and variance 1 normal distributions in both policy directions, which gives us $g$. Our choices for $d, E_{i}$ and $W$ have the correct qualitative properties, and the precise form has been chosen with computational reasons in mind. For computational reasons, we choose the $E_{i}$ to be identically distributed according to a Laplace distribution with density function $e^{-|t|} / 2 .{ }^{12}$ We use Euclidean distance squared as the distance function. Finally, we set $W(x)=e^{-x^{2} / 2}$.

With these choices, $0 \leq \tilde{U}_{i} \leq 1$ for all $i$ and all choices of policies $c_{1}, \ldots, c_{n} . \tilde{U}_{i}=1$ means that $100 \%$ of the votes go to candidates playing policy $\tilde{c}_{i}$. In this way, utility can conveniently

\footnotetext{
${ }^{11}$ Our model does not endogenize the entry and exist of new parties, in contrast to the citizen-candidate models (Besley and Coate, 1997; Osborne and Slivinski, 1996). Moreover, some spatial models allow entry. See Palfrey (1984) for one important example.

${ }^{12}$ Computing our utility functions is demanding, since they are double integrals that need to evaluated numerically. The situation is further complicated by the fact that the integrand includes $F$, which is a joint cumulative distribution function and, hence, typically taxing to compute. With the $E_{i}$ distributed according to a Laplace distribution, it turns out that $F$ has a closed formula that can be explicitly computed by hand and is inexpensive to compute.
} 
be interpreted as how satisfied politicians are with the (expected) election outcome, on a scale from $0 \%$ to $100 \%$.

\subsection{An Example with Two Parties}

We start with a case with two political parties. Figure 1 graphically illustrates the scenario that we have in mind. We assume that the candidates (the hollow circles) have symmetrical but opposite positions on the $x$-axis but identical positions on the $y$-axis. Concretely, we set

$$
\tilde{c}_{1}=(-0.5,1), \quad \tilde{c}_{2}=(0.5,1)
$$

The median voter (the solid dot) is placed in the middle of both the vertical and horizontal axes. Competition for votes leads to convergence towards the median voter along both dimensions, by Proposition 1. However, since politicians receive a higher utility from positions closer to their preferred policy, it would seem that they have incentives to collude on the $y$-axis, and one might suspect that the two parts of the dashed area on the left and right side of the $y$-axis are collusion regions. This turns out to be the case.

Figure 1. An example with two parties.

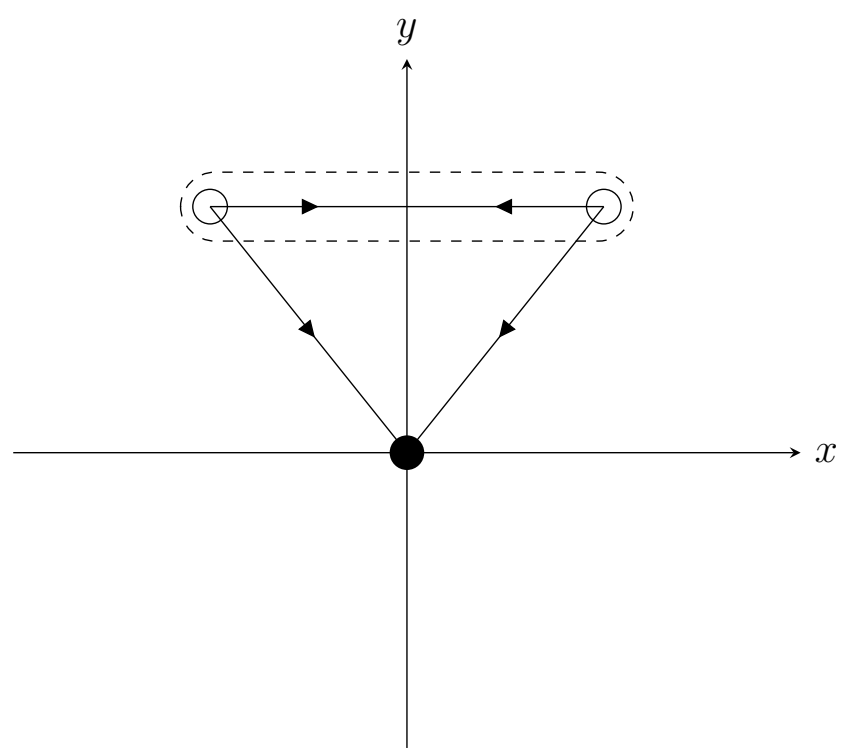


Let us now consider the simulation results. The regions $X_{1}=\{(t, 1) \mid-0.5 \leq t \leq 0\}$ and $X_{2}=\{(t, 1) \mid 0 \leq t \leq 0.5\}$ in $\mathbb{R}^{2}$ appear to be good candidates for collusion regions. The minimum utility for each candidate given a play $\left(c_{1}, c_{2}\right) \in X_{1} \times X_{2}$ is $\approx 0.814$. To show that these are collusion regions, we only need to exhibit a suitable threat. Here, threats are plentiful - even small movements towards the $x$-axis lead to lower utility. For example, if $c_{2}=(0.5,0.75)$, then $\tilde{U}_{1}$ is $\leq 0.807$, and this maximum is achieved close to $c_{1}=(-0.220,0.610)$. In particular, we see that a mild deviation serves as a threat. For a more destructive threat, one might take $c_{2}=(0.5,0)$. With this, $\tilde{U}_{1} \leq 0.534$. We also note that, by examining a sequence of best responses, it seems likely that for the one-shot game, there is an approximate Nash equilibrium close to $c_{1}=(-0.3,0.6), c_{2}=(0.3,0.6)$, with utility $\approx 0.85$. By contrast, the same type of analysis suggests that the (one-shot) restricted game has an approximate Nash equilibrium close to $c_{1}=(-0.233,1), c_{2}=(0.233,1)$, with utility $\approx 0.93$. It is a notable (general) feature of our model that equilibria are not convergent; in a convergent situation, candidates have an incentive to play a policy closer to their preference.

\subsection{Dynamics after the Entry of a Third Party}

Suppose now that a third candidate enters in the political arena. Tacit collusion theory would suggest that the entry of a candidate with the opposite preference on the $y$-axis might break the collusion. We now put this hypothesis to a test. Assume that the new candidate plays the policy

$$
c_{3}=(0,-1)
$$

Although we now have three candidates, we face a two-player game by fixing $c_{3}$ - but we need the three-candidate model to compute the expected vote shares and utilities.

First, we note that $X_{1}$ and $X_{2}$ still form a set of collusion regions. Indeed, $\tilde{U}_{i} \geq 0.433$ when $\left(c_{1}, c_{2}\right) \in X_{1} \times X_{2}$, but if $c_{2}=(0.5,0)$, then $\tilde{U}_{1} \leq 0.417$. When $\left(c_{1}, c_{2}\right) \in X_{1} \times X_{2}$, the maximum utility with symmetric policies around the $y$-axis is $\approx 0.511$, achieved when $c_{1} \approx$ 
$(-0.112,1)$ and $c_{2} \approx(0.112,1)$. The best response for $c_{2}=(0.112,1)$ is $c_{1} \approx(-0.369,0.419)$, with $\tilde{U}_{1} \approx 0.574$. Thus, we see that the collusion is not very strong. ${ }^{13}$

We end with further analysis to demonstrate that even if the collusion can in principle be upheld, there are very strong incentives for not doing so. First, some best response analysis suggests that the one-shot game has a number of approximate Nash equilibria. One is situated around $c_{1}=(-0.413,0.514), c_{2}=(0.413,0.514)$ with utility $\approx 0.504$, and there are others with similar values of the first coordinate. Thus, unless the discounting factor is exceptionally high, candidates are better off not attempting to collude. On the other hand, candidates 1 and 2 have some incentive to attempt to collude on a different policy on the $y$-axis. For example, fixing $y=0.5$, the maximum utility under symmetric policies is $\approx 0.555$, with $c_{1}$ and $c_{2}$ close to $(0,0.5)$, and this appears to be (approximately) the best $y$-value on which to attempt to collude. Thus, it is interesting to note that regardless of whether the candidates attempt to collude, they are very likely to adjust their policy in the $y$-direction to (very roughly) $y \approx 0.5$. On the other hand, they appear to be exhibiting the opposite behavior in the $x$-direction depending on whether they collude: If they collude, they move towards $x=0$, and if they do not, they move towards their preferred policy in the $x$-direction. In other words, if they collude, they will compete (rather fiercely) along the $x$-axis, but if they do not collude, they need to differentiate themselves more, to appeal to their "base".

To conclude the discussion, we graphically demonstrate the analysis above in Figure 2. The hollow circles are the two old candidates, and the black circle is the median voter. The gray dot illustrates the new candidate. The dashed area marks the new collusion region. The light gray lines show the movement of the candidates towards an approximate Nash equilibrium in a free competition equilibrium, whereas the black lines trace the movement towards an approximate Nash equilibrium under collusion.

\footnotetext{
${ }^{13}$ Note that in terms of votes, the situation is even more dire -if we had used the alternative utility function discussed above to indicate that candidates 1 and 2 desire a combined vote share of $>50 \%$, then the collusion would likely have broken down completely.
} 
Figure 2. Dynamics after the entry of a third party.

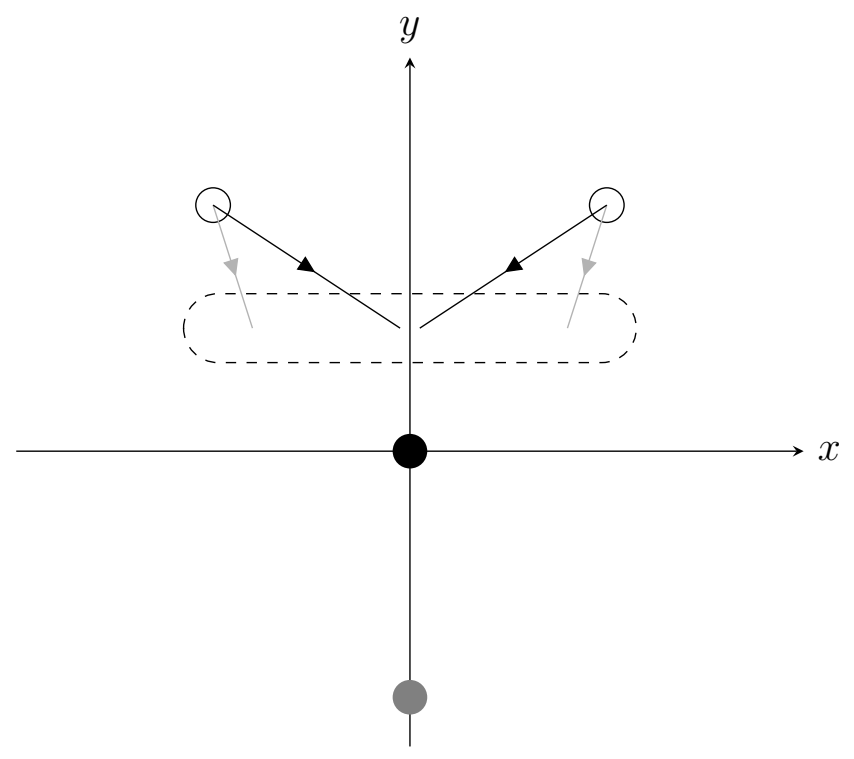

\section{Empirical Example: Policy Preferences of Swedish Politicians and Voters}

We conclude the paper by documenting patterns in survey data on Swedish politicians and voters. In particular, we show that Swedish politicians tend to have, on average, similar economic policy preferences as voters, but there is a large "preference gap" on other policy dimensions. These findings could be interpreted as tacit collusion among political parties, although there may be other explanations.

\subsection{Data}

We combine two different surveys on voters and politicians elected to the Swedish Parliament (Riksdag). For the voters, we use a survey by the SOM Institute that has been conducted since 1986 (University of Gothenburg, 2019). This survey is a yearly quasi-panel, with some questions being asked every year and some questions being replaced. We use a similar 
survey for the politicians, the Riksdag Survey, that has been conducted by the Department of Political Science at the University of Gothenburg. ${ }^{14}$

Both surveys are composed of a number of claims. We focus on four claims that concern salient policy issues that overlap between the voter and politician surveys and have been asked continuously over time. Two of these reflect economic left-right ideology, and they are "Reduce the public sector" and "Increase privatization of healthcare". The other two claims could be associated with social ideology. They are "Accept fewer refugees" and "Sweden should join the European Monetary Union/Adopt the euro as a currency". ${ }^{15}$ We observe the first three claims for all years 1994-2018 for voters and politicians. The last-mentioned claim was not included in the 1994 and 2018 surveys.

Voters and politicians both indicate their opinions on each claim on a 1-5 scale, where 1 implies strong agreement and 5 indicates strong disagreement. Table 1 reports the summary statistics on these variables. We also plot the evolution of policy positions over time in Appendix Figures A1 and A2.

Table 1. Summary statistics.

\begin{tabular}{lcccc}
\hline & Observations & Mean & Median & Std. dev. \\
\hline Panel A: Voters & & & & \\
$\quad$ Reduce public sector & 77052 & 3.3 & 3 & 1.20 \\
Privatize more healthcare & 59905 & 3.4 & 3 & 1.22 \\
Accept fewer refugees & 97565 & 2.6 & 3 & 1.29 \\
Join EMU & 51587 & 3.5 & 4 & 1.37 \\
\hline Panel B: Politicians & & & & \\
Reduce public sector & 2480 & 3.2 & 3 & 1.51 \\
Privatize more healthcare & 2488 & 3.1 & 3 & 1.52 \\
Accept fewer refugees & 2479 & 3.8 & 4 & 1.18 \\
Join EMU & 1573 & 2.9 & 3 & 1.53 \\
\hline
\end{tabular}

\footnotetext{
${ }^{14}$ The politician survey has had a relatively high response rate varying from $80 \%$ to $95 \%$.

${ }^{15}$ This dimension of ideology is commonly labeled as the GAL-TAN axis in political science, where GAL stands for green-alternative-liberal and TAN stands for tradionalist-authoritarian-nationalist, but we could also use other names. For instance, Goodhart (2017) uses the terminology "Somewhere-Anywhere".
} 


\subsection{Collusion in Swedish Politics?}

Figure 3 provides a first glance at the differences between voters' and politicians' average opinions. We divide politicians into three different groups: the left bloc (the Social Democrats, the Left Party, and the Green Party), the right bloc (the Center Party, the Liberal Party, the Moderate Party, and the Christian Democrats), and Sweden Democrats. This division reflects the stark division between socialist and non-socialist parties that has resulted into a stable two-bloc system (Alesina, Roubini and Cohen, 1997; Pettersson-Lidbom, 2008). We see that there is a relatively stable and small gap between voters and politicians in terms of their preferences for economic policies - reducing the size of the public sector or increasing the privatization of healthcare. However, when we consider attitudes towards reducing immigration or joining the EMU, the difference is striking until more recent years, when politicians' policy positions begin to move towards those of voters.

Figure 3. Voter and politician preferences over time.
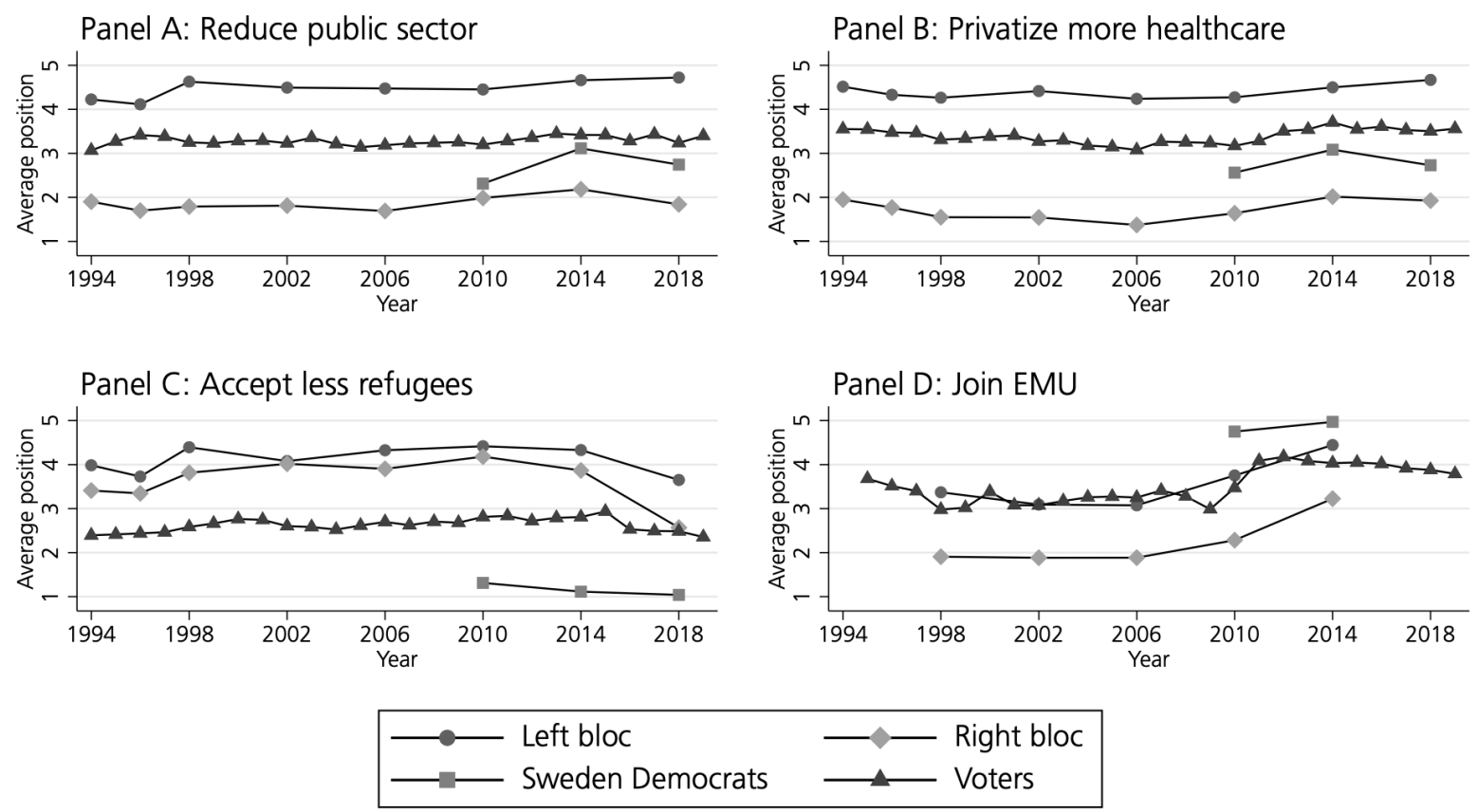

Notes: The left bloc parties are the Social Democrats, the Left Party, and the Green Party. The right bloc parties are the Center Party, the Liberal Party, the Moderate Party, and the Christian Democrats; 1 indicates a strong agreement with a statement and 5 indicates a strong disagreement with a statement. 
To further describe the preference gap between voters and politicians, we quantify the difference by estimating the following equation:

$$
Y_{i t}=\alpha_{i}+\beta \text { Politician }_{i t}+\theta_{t}+\varepsilon_{i t}
$$

Here, $Y_{i t}$ is the individual response to each of the survey questions, $\alpha$ is a constant, and $\beta$ is the coefficient of our interest. It tells us the average difference in voters' and politicians' opinions. To account for year-specific effects that are common to all respondents, we always control for year fixed effects, $\theta_{t}$. The survey data also contain information on voter and politician characteristics. In some specifications, we include a vector of control variables with controls for gender, the level of education (basic, high school, and university), and age (five age brackets). Moreover, we augment the baseline specification with region fixed effects. $\varepsilon_{i t}$ is an error term. Our estimation sample only includes years when surveys were conducted on both voters and politicians.

We estimate the model using OLS and ordered logit, first pooling together all data we have. These regression results are reported in Panels A and B, respectively, of Table 2. We see no statistically significant difference between politicians and voters regarding the size of the public sector (columns 1 and 2). Politicians are slightly more positive than voters regarding the privatization of healthcare (columns 3 and 4). Striking differences arise when we examine attitudes towards reducing immigration (columns 5 and 6). On average, the opinions of voters and politicians by nearly one point. We also observe a small difference in support for joining the EMU (columns 7 and 8). Note that in all specifications, including additional covariates barely changes the regression coefficients. ${ }^{16}$

\footnotetext{
${ }^{16}$ Appendix Table A1 reports the regression coefficients of the control variables. We also corroborate these findings with data on municipal politicians for whom we observe attitudes towards reducing the size of the public sector and reducing immigration for two years. We present the regression results in Table A2 and Figure A3. While limited in both time and scope, these regressions yield a similar result, namely that there is no difference between voters and politicians regarding the size of the public sector but a large difference regarding immigration.
} 
In light of our model, it is perhaps more intriguing to understand how these differences evolve over time when parties engage in repeated electoral competition. We thus run separate regressions for each year and plot the results in Figure 4. Echoing the earlier results, Panels A and $\mathrm{B}$ suggest that, on average, there are no major differences between politicians and voters in their opinions on reducing the public sector or increasing the privatization of healthcare. The estimates of the preference gap also remain stable throughout the time period that we observe. However, a vastly different observation arises from Panels $\mathrm{C}$ and $\mathrm{D}$. The average difference between politicians' and voters' opinions on reducing immigration is large, but it starts to diminish after 2010 and becomes nonexistent in 2018. Similarly, politicians and voters appear to differ in terms of their attitudes towards joining the EMU, with politicians having more positive views.

What could explain the changing pattern we see over time in these policy dimensions? Interestingly, the gap in opinions regarding immigration starts to diminish after 2010. This is when the right-wing populist party, the Sweden Democrats (Sverigedemokraterna), entered the parliament. The party holds considerably more critical views towards immigration than the established parties. Now, recall that our model predicts that when a political party with policy preferences closer to the median voter enters the political arena, collusion may break or become weaker, and other parties adjust their policy positions. This could be what happened in the Swedish case. The collapse in support for joining the EMU, on the other hand, could be due to the European debt crisis. As Figure 4 shows, both voter and politician opinions became less positive around this time period. These notions are in line with politicians colluding along some policy dimensions and taking policy positions that do not accord with voters' interests. However, this collusion could be upset by external events, eventually leading to (average) convergence of politician and voter opinions. ${ }^{17}$

\footnotetext{
${ }^{17}$ In Appendix Table A3 and Figure A4, we rerun our regressions using a sample that excludes politicians from the Sweden Democrats. The results suggests that some difference in terms of attitudes towards refugee intake remains, which implies that politicians have not fully adopted the voters' preferences.
} 
Table 2. Average preference gap between voters and politicians.

\begin{tabular}{|c|c|c|c|c|c|c|c|c|}
\hline & \multicolumn{2}{|c|}{ Reduce public sector } & \multicolumn{2}{|c|}{ Privatize more healthcare } & \multicolumn{2}{|c|}{ Accept fewer refugees } & \multicolumn{2}{|c|}{ Join EMU } \\
\hline & $(1)$ & $(2)$ & $(3)$ & $(4)$ & $(5)$ & (6) & $(7)$ & (8) \\
\hline $\begin{array}{l}\text { Panel A: OLS } \\
\text { Politician }\end{array}$ & $\begin{array}{l}-0.016 \\
{[0.032]}\end{array}$ & $\begin{array}{l}-0.007 \\
{[0.034]}\end{array}$ & $\begin{array}{c}-0.248^{* * *} \\
{[0.032]}\end{array}$ & $\begin{array}{c}-0.205^{* * *} \\
{[0.035]}\end{array}$ & $\begin{array}{c}1.198^{* * *} \\
{[0.025]}\end{array}$ & $\begin{array}{c}0.972^{* * *} \\
{[0.027]}\end{array}$ & $\begin{array}{c}-0.400 * * * \\
{[0.039]}\end{array}$ & $\begin{array}{c}-0.203^{* * *} \\
{[0.042]}\end{array}$ \\
\hline $\begin{array}{l}\text { Panel B: Ordered logit } \\
\text { Politician }\end{array}$ & $\begin{array}{c}0.040 \\
{[0.053]}\end{array}$ & $\begin{array}{c}0.046 \\
{[0.057]}\end{array}$ & $\begin{array}{c}-0.334^{* * *} \\
{[0.053]}\end{array}$ & $\begin{array}{c}-0.293^{* * *} \\
{[0.057]}\end{array}$ & $\begin{array}{c}1.692^{* * *} \\
{[0.038]}\end{array}$ & $\begin{array}{c}1.467^{* * *} \\
{[0.043]}\end{array}$ & $\begin{array}{c}-0.559 * * * \\
{[0.055]}\end{array}$ & $\begin{array}{c}-0.299^{* * *} \\
{[0.060]}\end{array}$ \\
\hline $\begin{array}{l}N \\
\text { Year FE } \\
\text { Controls }\end{array}$ & $\begin{array}{c}23344 \\
\checkmark\end{array}$ & $\begin{array}{c}21609 \\
\checkmark \\
\checkmark\end{array}$ & $\begin{array}{c}20739 \\
\checkmark\end{array}$ & $\begin{array}{c}19133 \\
\checkmark \\
\checkmark\end{array}$ & $\begin{array}{c}29191 \\
\checkmark\end{array}$ & $\begin{array}{c}27084 \\
\checkmark \\
\checkmark\end{array}$ & $\begin{array}{c}16356 \\
\checkmark\end{array}$ & $\begin{array}{c}15259 \\
\checkmark \\
\checkmark\end{array}$ \\
\hline
\end{tabular}

Notes: Additional controls include indicators for gender, educational attainment, age group, and geographical region. Robust standard errors are reported in brackets. $*, * *$ and $* * *$ denote statistical significance at $10 \%, 5 \%$ and $1 \%$, respectively

Figure 4. Preference gap between politicians and voters by year.
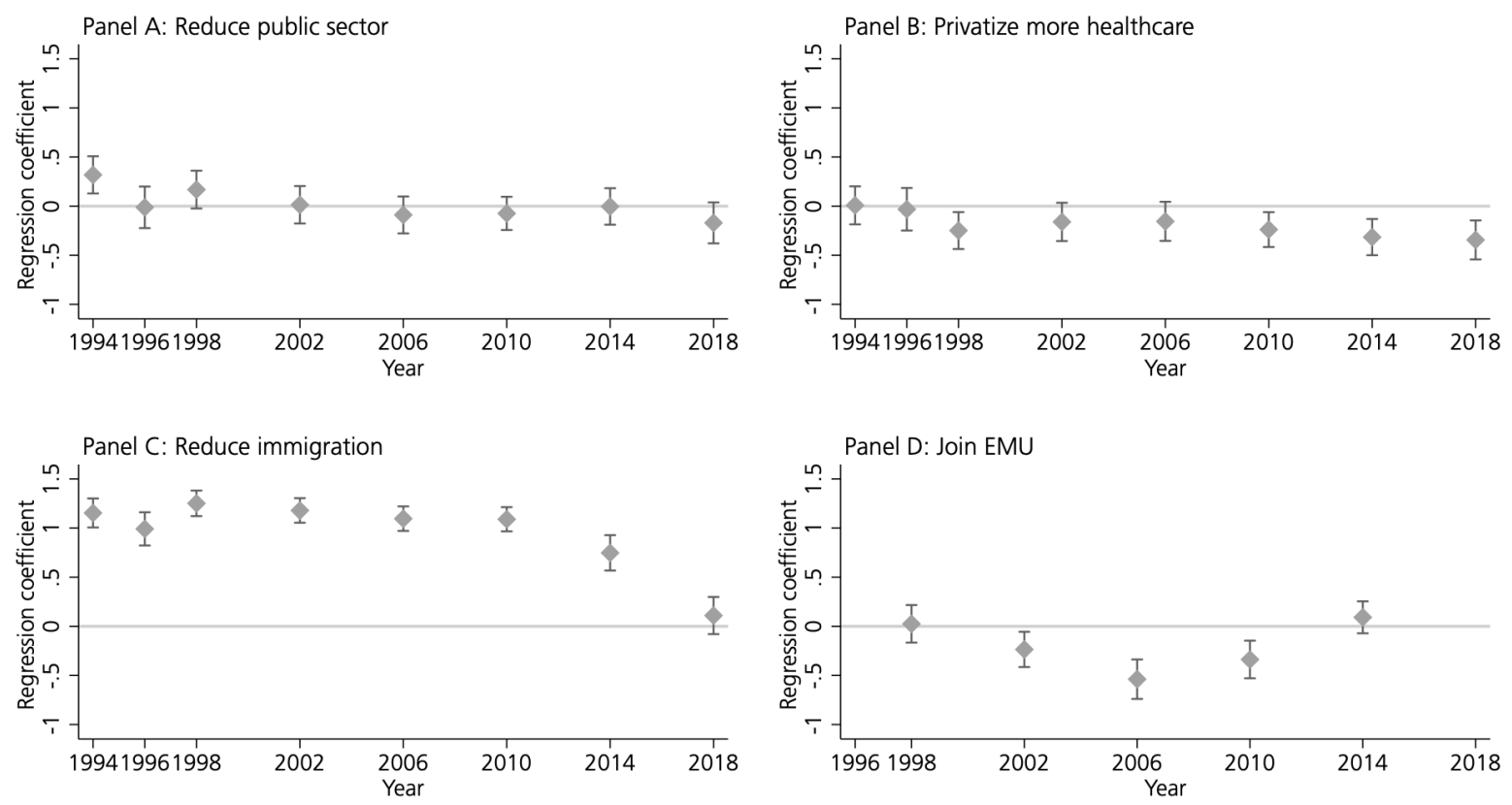

Notes: We report point estimates from separate regressions that use data from each survey year. We control for indicators for gender, educational attainment, age group, and geographical region. The figure also shows $95 \%$ confidence intervals that were constructed using robust standard errors. 


\section{Concluding Remarks}

Several authors have argued that politicians may engage in collusive behavior that goes against the public interest (e.g., Katz and Mair 1995; Crisp and Desposato 2004; Gottlieb 2015). How can we reconcile such behavior in democracies with competitive elections? It has also been shown that established political parties have reacted to the rise of challenger parties by shifting their policy positions along certain dimensions (e.g., Meijers 2017; AbouChadi and Krause 2020; Spoon and Klüver 2020). ${ }^{18}$ But why does this only happen after a new political party has entered politics?

We propose answers to these questions by studying the behavior of political parties in a model with probabilistic voting and repeated elections. Perhaps the most important feature of our model is that it allows us to characterize the conditions under which political parties form ideological cartels with one another. By colluding, they take policy positions that are beneficial to them but deviate from what the median voter would prefer. We also discuss when this collusion is likely to collapse. In particular, we use numerical examples to illustrate how the entry of new political parties might help break the collusion among established parties.

Although the entry of new parties is not endogenous in our model, existing industrialorganization research on tacit collusion suggests that further studying the entry of new parties would be one interesting avenue for future theoretical work. The number of competitors and barriers to entry can affect the sustainability of collusion in the context of firms, and intuitively, such factors could also be important in the political arena. ${ }^{19}$ Such a model could have implications for understanding the rapid rise of populist parties, which could be a result of previous collision among established parties that is broken up due to entry.

\footnotetext{
${ }^{18} \mathrm{~A}$ recent example would be the rise of populist parties in Western Europe and elsewhere. See Guriev and Papaioannou (Forthcoming) for a review on literature on populist parties.

${ }^{19}$ For instance, electoral thresholds could keep new entrants out of established parties' way. See also Tullock (1965) for a classic discussion of entry barriers in politics.
} 
Experimentalists have already tested ideas regarding collusion between firms in laboratory settings (see, for example, Holt 1995 for a review). ${ }^{20}$ In addition to further theoretically studying tacit collusion in politics, it could be interesting to assess whether electoral collusion would arise in the laboratory and under what conditions. While there already is considerable experimental research on electoral competition (e.g., Morton 1993), collusion between candidates warrants further attention.

\footnotetext{
${ }^{20}$ Dal Bó and Fréchette (2011) present experimental evidence on the evolution of cooperation in a setting with repeated games.
} 


\section{References}

Abou-Chadi, Tarik and Werner Krause. 2020. "The Causal Effect of Radical Right Success on Mainstream Parties' Policy Positions: A Regression Discontinuity Approach." British Journal of Political Science 50(3):829-847.

Adams, James. 1999. "Policy Divergence in Multicandidate Probabilistic Spatial Voting." Public Choice 100(1/2):103-122.

Adams, James. 2012. "Causes and Electoral Consequences of Party Policy Shifts in Multiparty Elections: Theoretical Results and Empirical Evidence." Annual Review of Political Science 15(1):401-419.

Ågren, Hanna, Matz Dahlberg and Eva Mörk. 2007. "Do politicians' preferences correspond to those of the voters? An investigation of political representation." Public Choice 130(12):137-162.

Aldrich, John H. 1995. Why Parties?: The Origin and Transformation of Political Parties in America. University of Chicago Press.

Alesina, Alberto. 1988. "Credibility and Policy Convergence in a Two-Party System with Rational Voters." American Economic Review 78(4):796-805.

Alesina, Alberto, Nouriel Roubini and Gerald D. Cohen. 1997. Political Cycles and the Macroeconomy. MIT Press.

Ansolabehere, Stephen and James M. Snyder. 2000. "Valence Politics and Equilibrium in Spatial Election Models." Public Choice 103(3/4):327-336.

Ansolabehere, Stephen, James M. Snyder and Charles Stewart. 2001. "Candidate Positioning in U.S. House Elections." American Journal of Political Science 45(1):136-159.

Ashworth, Scott and Ethan Bueno de Mesquita. 2009. "Elections with platform and valence competition." Games and Economic Behavior 67(1):191-216.

Bartolini, Stefano and Peter Mair. 2007. Identity, Competition and Electoral Availability: The Stabilisation of European Electorates 1885-1985. ECPR Press.

Besley, Timothy and Stephen Coate. 1997. "An economic model of representative democracy." Quarterly Journal of Economics 112(1):85-114.

Brander, James A. and Barbara J. Spencer. 1985. "Tacit collusion, free entry and welfare." Journal of Industrial Economics pp. 277-294.

Broockman, David E. and Christopher Skovron. 2018. "Bias in Perceptions of Public Opinion among Political Elites." American Political Science Review 112(3):542-563.

Bursztyn, Leonardo, Georgy Egorov and Stefano Fiorin. 2020. "From extreme to mainstream: The erosion of social norms." American Economic Review 110(11):3522-48.

Callander, Steven. 2008. "Political Motivations." Review of Economic Studies 75(3):671-697.

Calvert, Randall L. 1985. "Robustness of the Multidimensional Voting Model: Candidate Motivations, Uncertainty, and Convergence." American Journal of Political Science 29(1):69-95.

Crisp, Brian F. and Scott W. Desposato. 2004. "Constituency Building in Multimember Districts: Collusion or Conflict?" Journal of Politics 66(1):136-156.

Dahl, Robert A. 1956. A Preface to Democratic Theory. University of Chicago Press. 
Dal Bó, Pedro and Guillaume R. Fréchette. 2011. "The Evolution of Cooperation in Infinitely Repeated Games: Experimental Evidence." American Economic Review 101(1):411-29.

De Vries, Catherine E. and Sara B. Hobolt. 2020. Political Entrepreneurs. Princeton University Press.

Downs, Anthony. 1957. An Economic Theory of Democracy. New York: Harper and Row.

Duggan, John and César Martinelli. 2017. "The Political Economy of Dynamic Elections: Accountability, Commitment, and Responsiveness." Journal of Economic Literature 55(3):916-984.

Ferreira, Fernando and Joseph Gyourko. 2009. "Do political parties matter? Evidence from US cities." Quarterly Journal of Economics 124(1):399-422.

Fershtman, Chaim and Ariel Pakes. 2000. "A Dynamic Oligopoly with Collusion and Price Wars." RAND Journal of Economics 31(2):207-236.

Folke, Olle. 2014. "Shades of Brown and Green: Party Effects in Proportional Election Systems." Journal of the European Economic Association 12(5):1361-1395.

Gerber, Elisabeth R. and Jeffrey B. Lewis. 2004. "Beyond the median: Voter preferences, district heterogeneity, and political representation." Journal of Political Economy 112(6):1364-1383.

Goodhart, David. 2017. The road to somewhere: The populist revolt and the future of politics. Oxford University Press.

Gottlieb, Jessica. 2015. "The Logic of Party Collusion in a Democracy: Evidence from Mali." World Politics 67(1):1-36.

Grofman, Bernard. 2004. "Downs and Two-Party Convergence." Annual Review of Political Science 7(1):25-46.

Groseclose, Tim. 2001. "A Model of Candidate Location When One Candidate Has a Valence Advantage." American Journal of Political Science 45(4):862-886.

Guriev, Sergei and Elias Papaioannou. Forthcoming. "The Political Economy of Populism." Journal of Economic Literature .

Holt, Charles A. 1995. Industrial Organization: A Survey of Laboratory Research. In The Handbook of Experimental Economics, ed. John H. Kagel and Alvin E. Roth. Princeton University Press pp. 349-444.

Ivaldi, Marc, Bruno Jullien, Patrick Rey, Paul Seabright and Jean Tirole. 2003. "The Economics of Tacit Collusion." Final Report for DG Competition, European Commission. Available online at https://ec.europa.eu/competition/mergers/studies_reports/ the_economics_of_tacit_collusion_en.pdf (accessed February 25, 2020).

Katz, Richard S. and Peter Mair. 1995. "Changing Models of Party Organization and Party Democracy: The Emergence of the Cartel Party." Party Politics 1(1):5-28.

Kertzer, Joshua D. Forthcoming. "Re-Assessing Elite-Public Gaps in Political Behavior." American Journal of Political Science.

Knittel, Christopher R. and Victor Stango. 2003. "Price ceilings as focal points for tacit collusion: Evidence from credit cards." American Economic Review 93(5):1703-1729.

Lasch, Christopher. 1996. The Revolt of the Elites and the Betrayal of Democracy. WW Norton \& Company. 
Lee, David S., Enrico Moretti and Matthew J. Butler. 2004. "Do voters affect or elect policies? Evidence from the US House." Quarterly Journal of Economics 119(3):807-859.

Levitt, Steven D. 1996. "How do senators vote? Disentangling the role of voter preferences, party affiliation, and senator ideology." American Economic Review pp. 425-441.

Lin, Tse-Min, James M. Enelow and Han Dorussen. 1999. "Equilibrium in multicandidate probabilistic spatial voting." Public Choice 98(1-2):59-82.

Lindbeck, Assar and Jörgen W. Weibull. 1987. "Balanced-budget redistribution as the outcome of political competition." Public Choice 52(3):273-297.

MacLeod, W. Bentley and George Norman. 1987. "Competition, tacit collusion and free entry." Economic Journal 97(385):189-198.

Meijers, Maurits J. 2017. "Contagious Euroscepticism: The impact of Eurosceptic support on mainstream party positions on European integration." Party Politics 23(4):413-423.

Morton, Rebecca B. 1993. "Incomplete Information and Ideological Explanations of Platform Divergence." American Political Science Review 87(2):382-392.

Myerson, Roger B. 1993. "Effectiveness of Electoral Systems for Reducing Government Corruption: A Game-Theoretic Analysis." Games and Economic Behavior 5(1):118-132.

Osborne, Martin J. and Al Slivinski. 1996. "A model of political competition with citizencandidates." Quarterly Journal of Economics 111(1):65-96.

Palfrey, Thomas R. 1984. "Spatial Equilibrium with Entry." Review of Economic Studies 51(1):139-156.

Pereira, Miguel M. Forthcoming. "Understanding and Reducing Biases in Elite Beliefs About the Electorate." American Political Science Review .

Persson, Torsten and Guido Enrico Tabellini. 2002. Political economics: explaining economic policy. MIT press.

Pettersson-Lidbom, Per. 2008. "Do parties matter for economic outcomes? A regressiondiscontinuity approach." Journal of the European Economic Association 6(5):1037-1056.

Rydgren, Jens. 2007. "The Sociology of the Radical Right." Annual Review of Sociology 33:241-262.

Seror, Avner and Thierry Verdier. 2018. "Multi-Candidate Political Competition and the Industrial Organization of Politics." Available online at https://papers.ssrn.com/ abstract=3235604 (accessed May 16, 2021).

Spoon, Jae-Jae and Heike Klüver. 2020. "Responding to far right challengers: does accommodation pay off?" Journal of European Public Policy 27(2):273-291.

Stokes, Donald E. 1963. "Spatial Models of Party Competition." American Political Science Review 57(2):368-377.

Tullock, Gordon. 1965. "Entry Barriers in Politics." American Economic Review 55(1/2):458466.

University of Gothenburg. 2019. "The National SOM Survey Cumulative Dataset 1986-2019." van der Brug, Wouter. 2004. "Issue ownership and party choice." Electoral Studies 23(2):209233.

Weber, Shlomo. 1992. "On Hierarchical Spatial Competition." Review of Economic Studies 59(2):407-425. 
Weingast, Barry R. and William J. Marshall. 1988. "The Industrial Organization of Congress; or Why Legislatures, Like Firms, Are Not Organized as Markets." Journal of Political Economy 96(1):132-163.

Wittman, Donald. 1983. "Candidate Motivation: A Synthesis of Alternative Theories." American Political Science Review 77(1):142-157. 


\section{Online Appendix: Additional Figures and Tables}

Figure A1. Voter preferences
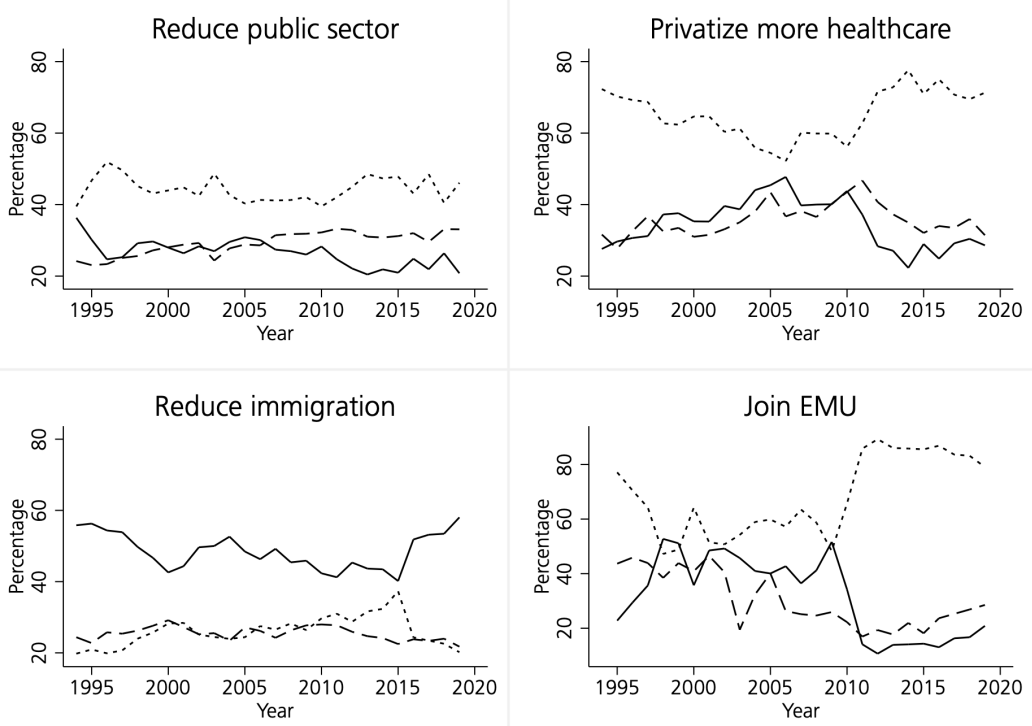

Solid line: Good idea. Dashed line: Neutral idea. Dotted line: Bad idea.

Figure A2. Politicians preferences
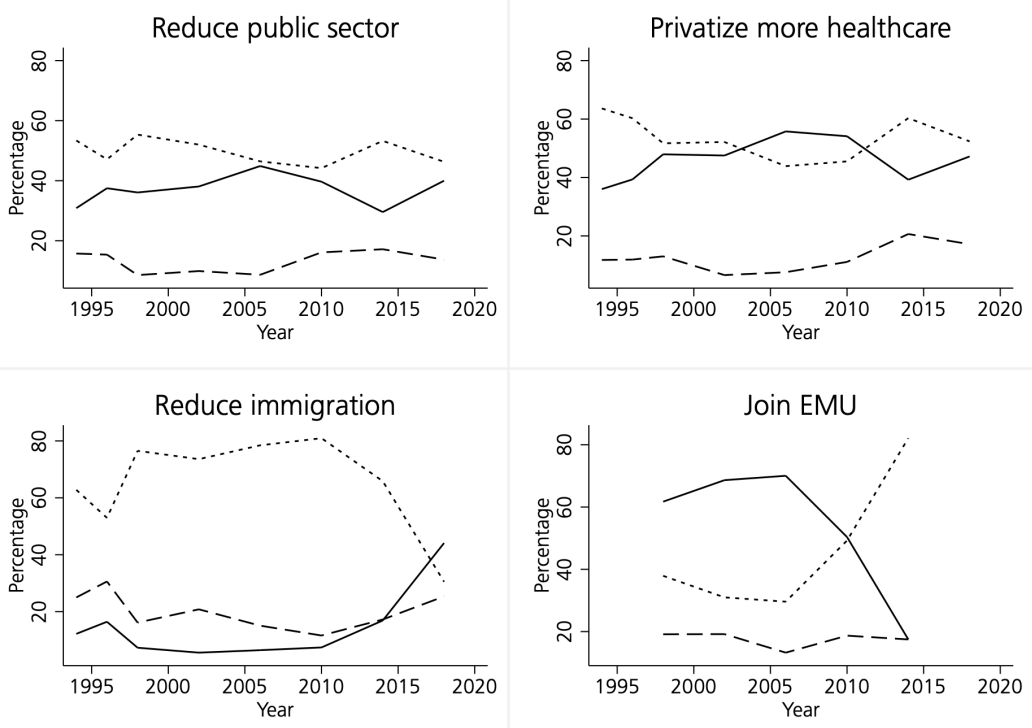

Solid line: Good idea. Dashed line: Neutral idea. Dotted line: Bad idea. 


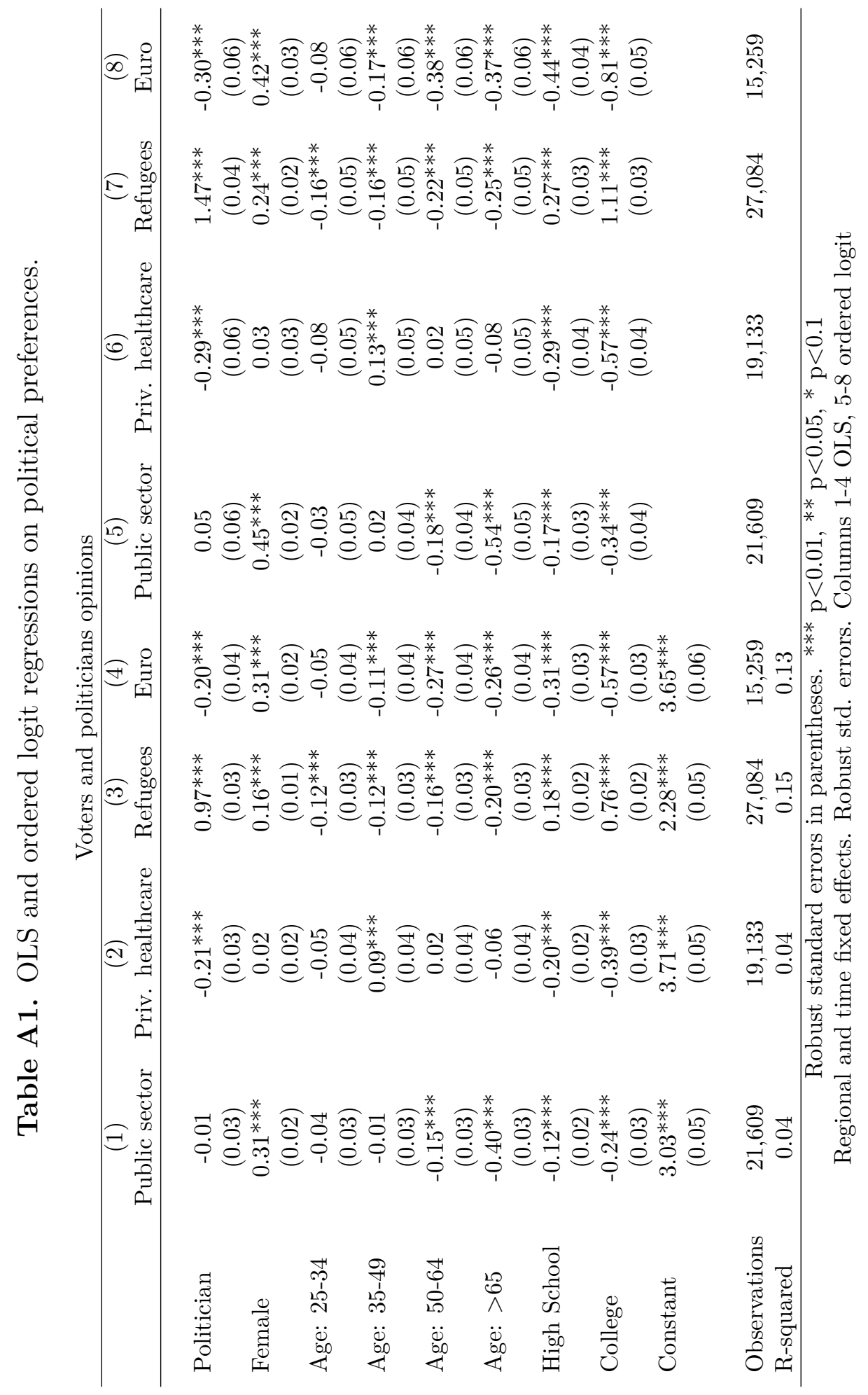

OA-2 
Table A2. OLS and ordered logit regressions on voters and municipal politicians.

\begin{tabular}{|c|c|c|c|c|}
\hline & $\begin{array}{c}(1) \\
\text { Public sector }\end{array}$ & $\begin{array}{c}(2) \\
\text { Refugees }\end{array}$ & $\begin{array}{c}(3) \\
\text { Public sector }\end{array}$ & $\begin{array}{c}(4) \\
\text { Refugees }\end{array}$ \\
\hline Municipality politician & $\begin{array}{c}0.03 \\
(0.02)\end{array}$ & $\begin{array}{c}0.80 * * * \\
(0.02)\end{array}$ & $\begin{array}{c}0.07^{* * * *} \\
(0.02)\end{array}$ & $\begin{array}{c}1.15^{* * *} \\
(0.03)\end{array}$ \\
\hline Female & $\begin{array}{c}0.31^{* * *} \\
(0.02)\end{array}$ & $\begin{array}{c}0.24^{* * *} \\
(0.01)\end{array}$ & $\begin{array}{c}0.43^{* * *} \\
(0.02)\end{array}$ & $\begin{array}{c}0.34^{* * *} \\
(0.02)\end{array}$ \\
\hline Age: $25-34$ & $\begin{array}{c}0.13^{* * * *} \\
(0.05)\end{array}$ & $\begin{array}{l}0.09 * \\
(0.05)\end{array}$ & $\begin{array}{c}0.18^{* * *} \\
(0.06)\end{array}$ & $\begin{array}{c}0.12 \\
(0.08)\end{array}$ \\
\hline Age: $35-49$ & $\begin{array}{l}-0.02 \\
(0.04)\end{array}$ & $\begin{array}{l}0.06 \\
(0.04)\end{array}$ & $\begin{array}{l}-0.03 \\
(0.06)\end{array}$ & $\begin{array}{l}0.06 \\
(0.07)\end{array}$ \\
\hline Age: $50-64$ & $\begin{array}{l}-0.05 \\
(0.04)\end{array}$ & $\begin{array}{l}-0.04 \\
(0.04)\end{array}$ & $\begin{array}{l}-0.06 \\
(0.06)\end{array}$ & $\begin{array}{l}-0.10 \\
(0.07)\end{array}$ \\
\hline Age: $>65$ & $\begin{array}{c}-0.39 * * * \\
(0.04)\end{array}$ & $\begin{array}{c}-0.26^{* * *} \\
(0.05)\end{array}$ & $\begin{array}{c}-0.52^{* * *} \\
(0.06)\end{array}$ & $\begin{array}{c}-0.40^{* * *} \\
(0.07)\end{array}$ \\
\hline High School & $\begin{array}{c}-0.13^{* * *} \\
(0.02)\end{array}$ & $\begin{array}{c}0.10^{* * * *} \\
(0.02)\end{array}$ & $\begin{array}{c}-0.18^{* * *} \\
(0.03)\end{array}$ & $\begin{array}{c}0.14^{* * *} \\
(0.03)\end{array}$ \\
\hline College & $\begin{array}{c}-0.32^{* * * *} \\
(0.02)\end{array}$ & $\begin{array}{c}0.44^{* * * *} \\
(0.02)\end{array}$ & $\begin{array}{c}-0.44^{* * *} \\
(0.03)\end{array}$ & $\begin{array}{c}0.64^{* * *} \\
(0.03)\end{array}$ \\
\hline Constant & $\begin{array}{c}3.80^{* * *} \\
(0.69)\end{array}$ & $\begin{array}{c}1.87^{* * *} \\
(0.56)\end{array}$ & & \\
\hline Observations & 27,285 & 27,485 & 27,285 & 27,485 \\
\hline R-squared & 0.04 & 0.15 & & \\
\hline
\end{tabular}

Figure A3. Time-dependent OLS regressions for voters and municipal politicians.
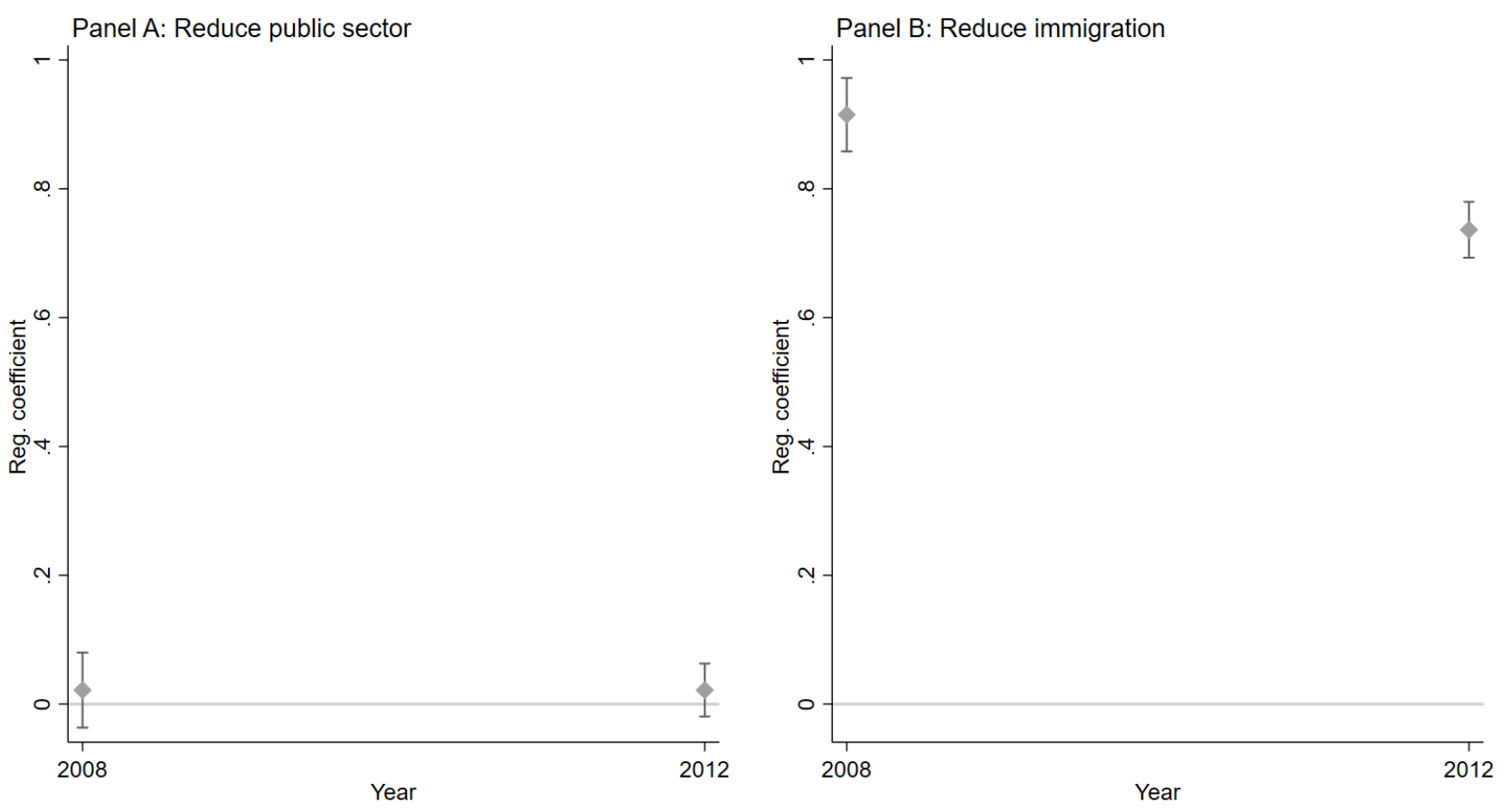


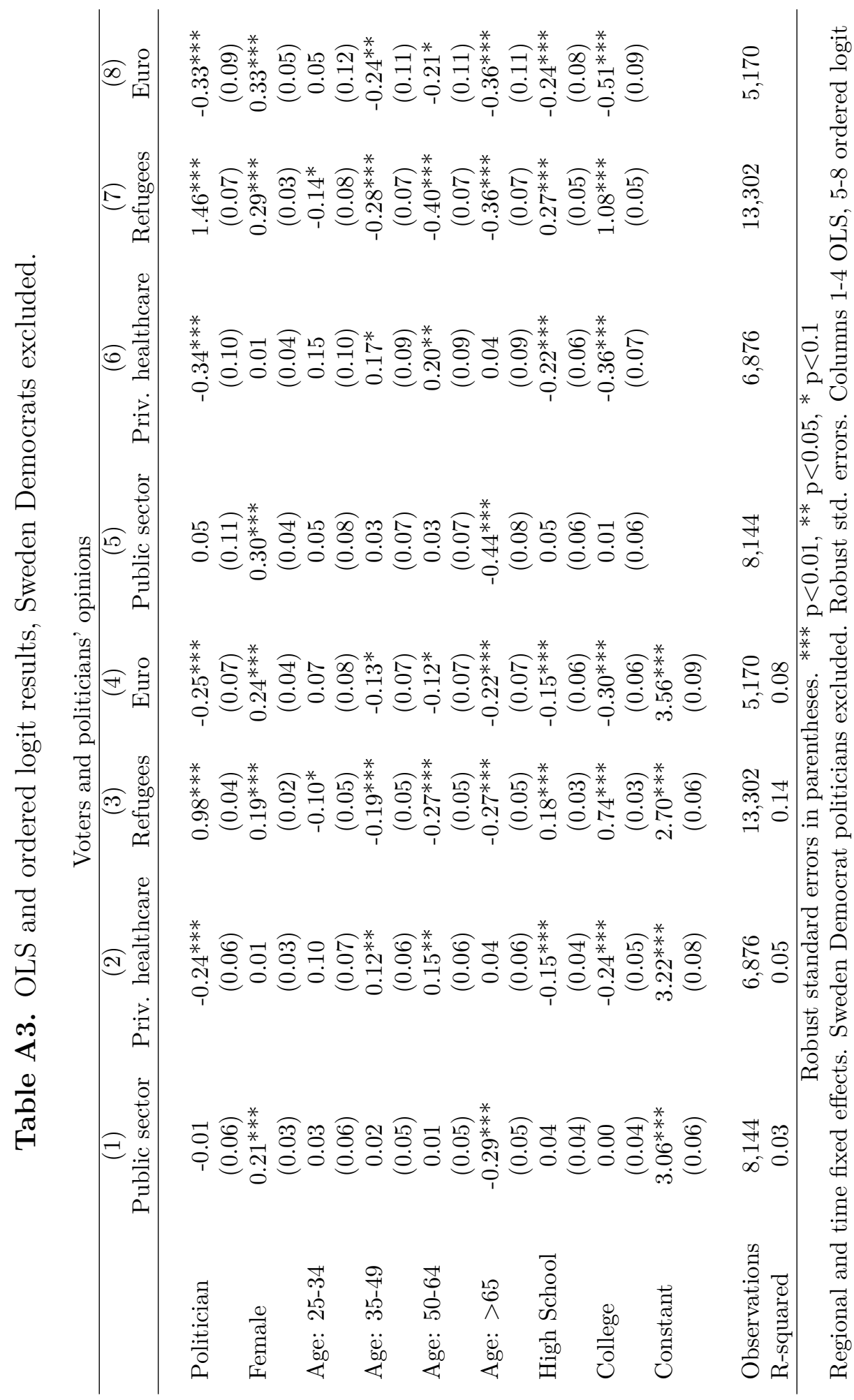


Figure A4. Preference gap between politicians and voters by year, Sweden Democrat politicians excluded.
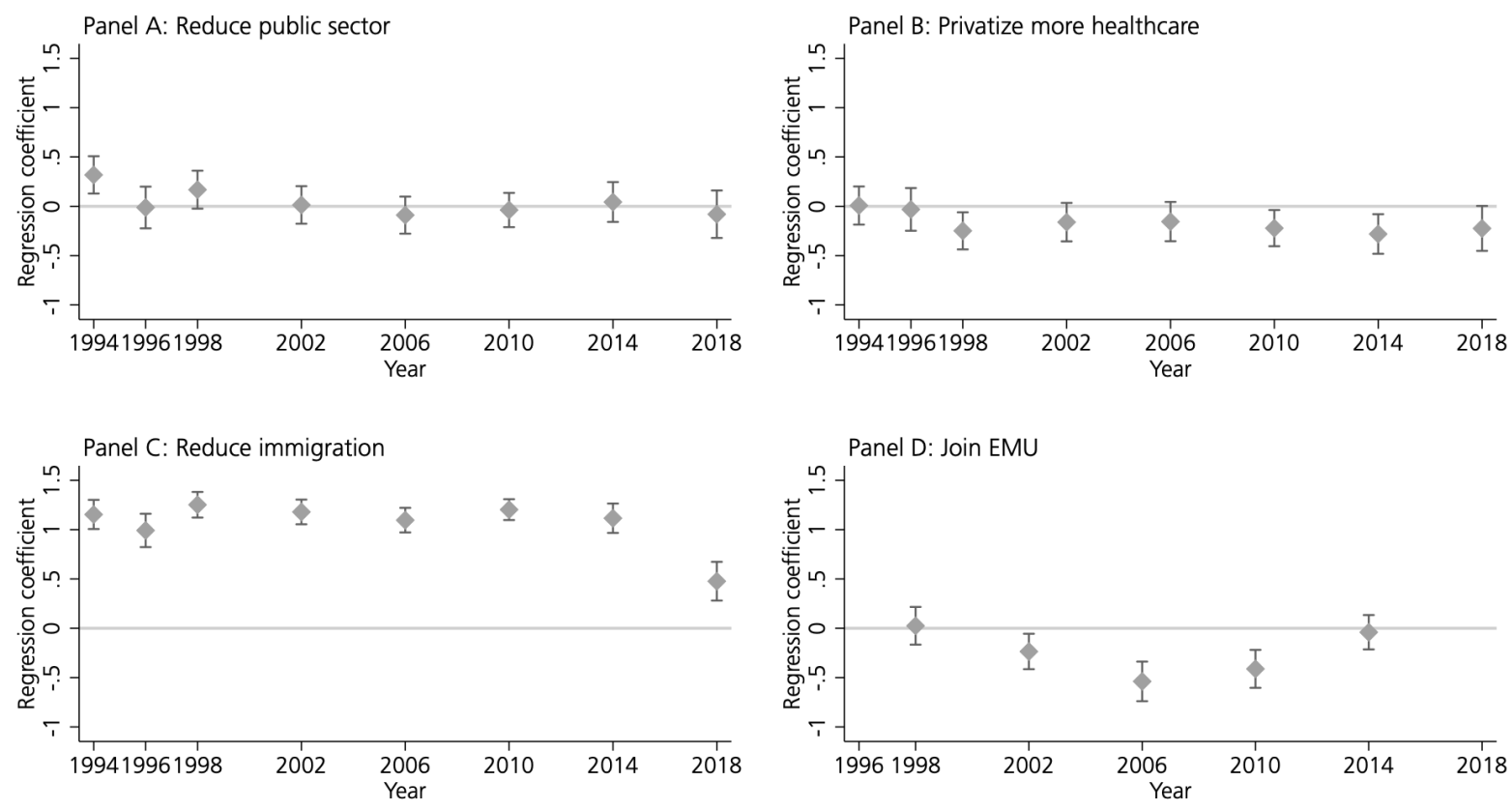